\title{
Why Finance Needs Philosophy (and Vice Versa): Some Epistemic and Methodological Issues
}

\author{
Emiliano Ippoliti ${ }^{1}$ (D)
}

Accepted: 20 June 2021 / Published online: 3 July 2021

(c) The Author(s) 2021

\begin{abstract}
As the world economy has for better or worse become more and more dependent on the financial markets, a rethinking of the role of finance in both theory and practice is necessary. I argue that such a rethinking requires a new look at the theories of finance that is philosophical in kind. In effect, as Martha Nussbaum claims, if the absence of philosophy in economics is arguably one of the main reasons for the flaws in certain economic theories, the absence of philosophy in finance is one the main reasons for the flaws in our theories on financial systems. In this paper I discuss the mutual relations and benefits between finance and philosophy. First, I examine the contribution that philosophy can offer to finance by analyzing a few critical issues in financial ontology (Section 2.1), financial methodology (Section 2.2) and financial mathematics (Section 2.3). I argue that philosophy is essential to enabling finance to achieve the goals for which it was designed, not only because it is a valuable external addition, but also internally, since philosophy is the proper tool for bringing about new theories and approaches. Then, I examine the contribution that finance can offer to philosophy by analyzing the relationship between theory and practice (Section 3.1), data and hypothesis (Section 3.2), and prediction, description and control (Section 3.3) in the context of financial systems. I argue that finance can help us to rethink some philosophical tenets on these issues.
\end{abstract}

Keywords Philosophy $\cdot$ Finance $\cdot$ Ontology $\cdot$ Methodology $\cdot$ Stock markets

\section{Economics, Finance and (the Absence of) Philosophy}

The ascent of finance has changed not only the economy, but the entire society, which have become more and more dependent on the financial markets, for better or worse. Finance is nowadays crucial for our individual and collective life and it deeply affects several dimensions of our prospects, from our education and working life to our psychological, ethical, epistemic well-being. Thus, this multi-dimensional nature of finance demands a rethinking of its role not only in both theory and practice, but also in society and culture in order to better understand and guide it. In particular, I argue that such a rethinking requires a fresh

Emiliano Ippoliti

emiliano.ippoliti@uniroma1.it

1 Sapienza University of Rome, Rome, Italy 
look at the theories on finance and stock markets-a look that is philosophical in kind, since philosophy can provide us with a proper and fruitful multi-dimensional exploration of them.

It is worth recalling the relation between philosophy and economics, from which finance stems, has affected the evolution of both the disciplines. On the one hand, economics provides continual inputs to philosophy. A typical example is the economics' treatment of concepts of rationality and choice, which have deep impact on the philosophy of mind and cognitive science (see e.g. Ross, 2005). On the other hand, economics was born out of philosophy, as Martha Nussbaum (2016) reminds us. Notwithstanding, the marginalist revolution (Walras, 1900) and the rise of neoclassical economics produced a well-known, gradual departure of economics from philosophy. This departure is considered by Nussbaum as one of the main reasons for a lack of real intellectual progress in economics. For example:

accounts of welfare and development that are produced without the active and ongoing participation of philosophy leave a lot to be desired. Embarking on serious work on these foundational questions will not be a picnic because they are foundational, and once an economist has really grappled with them, it may turn out that a good deal that has already been done will need to be redone (Nussbaum, 2016, p: 244).

Nussbaum displays several areas in which the study of human development needs continual inputs from philosophy. In these areas, philosophy can act as a foundational tool, that is, as a way to improve, clarify, and understand the system.

An important contribution to the relation between the two disciplines comes from the 'naturalistic turn' in philosophy. ${ }^{1}$ In a nutshell, naturalism maintains that reality, both existential and cognitive, must be explained in natural terms because there is nothing beyond nature that we can scientifically explore: "Certe ultra naturam nihil [Certainly, nothing beyond nature]" as Francis Bacon state his De dignitate et augmentis scientiarum. So, the naturalistic turn has reshaped the interaction between philosophy and the sciences by strongly assimilating them: they are conceived in continuity, as pursuing essentially the same aims through the same methods.

Therefore, on one hand, philosophy employs methods and hypotheses from economics in order to pose and solve problems and, on the other hand, economics benefits from philosophy too. In particular, the naturalistic turn has affected economic methodology by shifting the focus on the economic practice (see McCloskey, 1998). A remarkable example in this sense is the construction and use of economic models (Callon, 1998; MacKenzie, 2006) and the status of choice theory, which are largely influenced by recent advancements in the philosophy of action (see Ross, 2005).

In more detail, there are at least two ways of characterizing naturalism in philosophy. The first is the Quine's way (Quine, 1981), the other one is the Dewey's way (see Dewey, 1920; Cellucci, 2017).

In a nutshell, Quine's naturalism maintains that:

1. Philosophical issues have to be approached using our present scientific tools, methods and theories.

2. Epistemology is contained in natural science simply as a chapter of psychology.

$\overline{1}$ See also Hédoin (2012) on this point. 
Now, Quine claims that "the only point of view" the naturalist philosopher can offer is "the point of view of our own science" (Quine, 1981, p: 181). In particular, a naturalist philosopher provides the view of the present sciences: he "begins his reasoning within the inherited world theory," that is, within the niche of theory offered by the present sciences, and "tries to improve, clarify, and understand the system from within" (Cellucci, 2017, p: 72). Therefore, "according to Quine, the task of the naturalist philosopher is to improve, clarify, and understand the world theory of the present sciences from within" (Ibid.).

The other version of naturalism (Dewey-Cellucci) maintains that Quinean approach is defective since "improving, clarifying, and understanding the inherited world theory is an integral part of the scientists' work, and scientists are much more competent to the task than philosophers, who do not have the necessary qualification. Moreover, it is limiting to say that the only point of view the naturalist philosopher can offer is the point of view of the present science" (Ibid.). As a matter of fact, philosophy deals with problems that the present sciences are unable to treat and, when successful, may even produce to new sciences and theories. Thus, this view maintains that:

(a) Philosophical problems cannot be approached and solved only by means of the present sciences because, if that were so, philosophy would simply be subservient to the sciences.

(b) Philosophy is crucial to dealing with problems at the frontier of knowledge- while in Quine's approach, philosophy could not generate new sciences since epistemology is simply a chapter of psychology.

This form of naturalism seems more appropriate to advance finance and its philosophical investigation, since it conceives of philosophy as a way of approaching problems that these disciplines could not tackle by themselves.

In effect, we have remarkable examples of how philosophy helps to create new theories also in finance. Three significant examples are the performative theory (Austin, 1962; Callon, 1998; MacKenzie, 2006), reflexivity theory (Flanagan, 1981; Merton, 1948; Popper, 1957; Soros, 1987), and the philosophical reflection on cryptocurrency (see Sect. 2).

Thus, if the departure of economics from philosophy (and history) can be regarded à la Nussbaum as a main reason for the flaws of many economic theories, the flaws of financial theory may be better understood by taking a philosophical perspective that can also provide us with tools to guide them. To this end, in the next sections I examine several issues in finance that require a philosophical exploration, and I will focus on both sides of the relation between philosophy and finance, that is, what philosophy offers to finance that it should take into consideration, and vice versa. Of course, this examination is not exhaustive, ${ }^{2}$ but aims at outlining some fruitful lines of research inspired by the interaction between philosophy and finance.

First, I examine the contribution that philosophy offers to finance by analyzing a few critical epistemic and methodological issues ${ }^{3}$ in financial theory-building (Sect. 2.1), financial ontology (Sect. 2.2), financial methodology (Sect. 2.3) and financial mathematics

\footnotetext{
${ }^{2}$ For instance, I will not consider here the issues raised by computer science and cognitive science in financial, the notion explanation in financial systems, and the relation between philosophy and investment strategies.

3 The ethical issues in finance are beyond the scope of this paper-but for an overview, see de Bruin et al. (2020).
} 
(Sect. 2.4). I argue that philosophy is essential to enable finance to achieve a few goals for which it has been designed, not only as an external valuable addition, but also as an internal one. Then, I examine the contribution that finance can offer to philosophy by analyzing issues like the relation between theory and practice (Sect. 3.1), data and hypothesis (Sect. 3.2), and prediction, description and control (Sect. 3.3) in the light of financial systems. I argue that finance can help us to rethink a few tenets about these issues.

\section{Philosophy for Finance}

Philosophy has contributed to finance repeatedly in the past and played a crucial role in the ascent of financial systems: in effect, their acceptance and dissemination is largely due to a gradual change in the philosophical and moral attitudes towards them (see e.g. Brook, 2011; De Bruin et al., 2020; Ferguson, 2008).

In particular, we can break down the philosophical-historical attitude to finance into three main branches: the radically negative, the pragmatically moderate, and the generally positive.

The first, the radically negative one, considers the financial systems as an evil—or as a 'sin' in a few religions - as for example advocated by Aristotle in his Politics. Aristotle argues that finance can be productive, but he maintains that it introduces forms of gain,

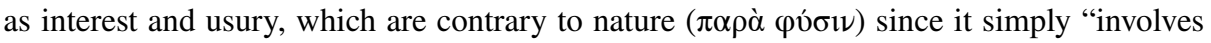
human beings taking things from one another" (Politics, 1.1258a): their "gains come from money itself and not from that for the sake of which money was invented. For money was brought into existence for the purpose of exchange, but interest increases the amount of the money itself" (Politics, 1.1258b). As a matter of fact, to be in accordance with nature

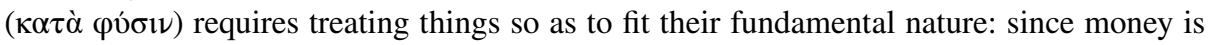
not a good in itself but only a medium of exchange, it is unnatural to make money as an end in itself. Consequently "this form of the business of getting wealth is of all forms the most contrary to nature" (Ibid.) and at least certain forms of finance should be banned.

The pragmatically moderate view revises this position and basically considers finance as a necessary evil (Keynes, 1936; Kinley, 2018). In effect, even if finance could not be good in itself, it is necessary since borrowing money is socially and economically useful because it addresses income or wealth shortages, enables long-term investment, and supports economic growth. In this sense, finance can be a means to move towards a better world, where the 'evil' on which it thrives-self-interest, greed, short-termism, adventurism, low sense of responsibility, excessive risk-taking-will be overcome.

The generally positive view goes beyond these two stances and considers finance not only as a propellant for economic growth, a "golden straitjacket" (Friedman, 1999), but it also argues for the centrality of finance to all elements of human history (Ferguson, 2008). This approach maintains that the path to economic prosperity is clear albeit narrow and may also require to satisfy global investors whose identity is unknown.

Now, the conceptual and historical transition from the first to the third stance was made possible by a series of philosophical and theorical turns. Two remarkable examples are the gradual distinction between interest and usury, and the revision of the relation between self-interest and public good.

In the first case, the acceptance and dissemination of finance draw on the practical and moral separation between the notions of interest and of usury (see e.g. de Bruin et al., 2020; Garonna \& Spaolonzi, 2016; Persky, 2007). This distinction, substantiated in Late 
Middle Ages and Renaissance, backed the idea that a form of compensation (the interest, that is, the acceptable payment on a loan) has to be considered as legitimate for those who lend money since a lender can suffer large losses by participating (indirectly) in many of the risks that the borrower takes. On the other hand, in many cases borrowers could not even do their business without a loan. So, risk and benefits are mutual and have to be shared and rewarded. Once this distinction has been drawn, finance can be accepted as a means to create prosperity and well-being, at least to a certain extent. Of course, the key issue here is quantitative in kind, that is, how much interest can be charged. In effect, interest and usury have been defined and measured in different ways in different societies and periods. Nevertheless, the conceptual novelty here is the change in attitude, namely the moral acceptability and distinction between what is allowed, and possibly good (interest), and what is not, and therefore bad (usury).

In the second case, a philosophical and practical rearrangement of the relation between public good and self-interest gave further support to the acceptability and dissemination of finance. A stock example in this sense is the introduction of the notion of the invisible hand' by Adam Smith (1759). In effect, this notion implies that the basis of finance, i.e. self-interest, can promote public good in the sense that self-interest elevates the economic well-being, and in part also the social one, despite the fact that individuals do not intentionally aim to achieving it. Although we know that the invisible hand and the formal results supporting it are controversial (see e.g. Stiglitz, 1994), they played an important role in disseminating the idea that finance is acceptable and not contrary to common good.

Nowadays, the financialization of the word, the controversial process that makes finance an organizing principle of modern societies (Epstein, 2005), has intertwined finance with every aspects of the life of people, institutions and societies, up to a point that the financial system raises many issues that are prominently philosophical in kind, that is, ethical, epistemological, methodological (see De Bruin et al., 2020; Ippoliti, 2020a for an overview).

Nonetheless, the financial systems, ultimately, are manufactured by human beings and then they can be continually modified and improved, and philosophy can be a guide to do this and to put us in a position to better understand them by examining not only what financial systems are, but also what they could and should be.

Moreover, philosophy can help finance to deal with the three main aspects involved in the construction of a theory, with which finance as a scientific field is particularly struggling, namely, the ontology, the epistemology and the methodology of financial markets. In this respect, finance is characterized by the presence of many theories and this variety indicates that a philosophical reflection on the making of financial theories is not only useful but also necessary. In fact, logic and philosophy can contribute in a decisive way to the pursuit of a goal that finance as a discipline is longing, and struggling, to achieve: the construction of a (more) robust theory accounting for financial and stock markets.

Stock market is a paramount example in this respect as it is populated by many different theories that compete and that are characterized by various ontological, methodological, and epistemological commitments, such as the efficient markets theory (e.g. Fama, 1970), the reflexive markets theory (e.g. Soros, 1987), the financial instability theory (Minsky, 1980), the econo-physics theory (Sornette, 2003), the behavioral theory (e.g. Ackert \& Deaves, 2009), the adaptive markets theory (Lo, 2004), ${ }^{4}$ the performative theory (Callon, 1998; MacKenzie, 2006), and the narrative theory (Shiller, 2019) to mention only the main

\footnotetext{
${ }^{4}$ For an evolutionary perspective that see finance as a cognitive niche, possibly maladaptative (a degenerative cognitive niche) see Bertolotti and Magnani (2017).
} 
ones. Some of these theories are the direct outcome of a new philosophical framework, like the aforementioned reflexivity theory or the performative theory.

All these different theories are not necessarily in conflict with each other: some may be complementary or point to different aspects of the same situation and so give us different viewpoints of several settings of financial entities or problems.

Such a variety of financial theories raises problems that are typically approached by philosophy (and philosophy of science in particular), such as their eventual integration or unification, their conceptual and empirical relations, and the relation between the data and hypothesis. Therefore, the tools that logic and philosophy of science have developed can contribute to advance our knowledge and understanding of both financial markets and financial theories. For instance, the Efficient Market Hypothesis and the Reflexive Market Hypothesis are contrasting theories under many aspects, and a clarification of their mutual relations, scopes, ontologies and methodologies would help clarify the extent to which they are in contrast or not, and how they could be integrated in order to achieve a better understanding of financial dynamics. ${ }^{5}$

In addition, one of the main functions of philosophy is to generate new theories or approaches, as the naturalistic approach à la Dewey-Cellucci argues, and philosophy has already shown its power in this sense. Three remarkable examples in finance, as we have anticipated, are the performative theory, the reflexivity theory and cryptocurrency theories.

Performative theory is the prototype of fruitfulness of a philosophical approach to economic and financial issues. In effect, this theory is the outcome of the 'journey' of the concept of performativity, which initiated with the philosophy of language (Austin, 1962; Searle, 1969) and ended up permeating finance (McKenzie, 2006) via anthropology (Butler, 1990) and sociology (Callon, 1998; Latour, 2005). The original philosophical issue, that is, the power of language of changing the world, is gradually transferred to economics and finance in order to examine how theoretical device used to describe a target system (e.g. a model) turns up to be a way of modifying it.

Reflexivity theory (Flanagan, 1981; Merton, 1948; Popper, 1957; Soros, 1987) is another remarkable example of a philosophical issue, that is, the study of the 'oedipal' effect in the social science put forward by Popper, which ended up permeating and characterizing a prominent way of conceptualizing and practicing finance (see Soros, 1987). In this case, the original philosophical issue, that is, the 'reflexive prediction' - the effect of a prediction over the precited event-was examined in economics by Grunberg and Modigliani (1954) and Simon (1954), and then approached by Soros (1987) in finance and stock markets, so as to shed light on the feedbacks mechanisms of (alleged) causes and effects, and their way of working and limits.

In the case of crypto currencies, it worth noting that a philosophical and theoretical reflection on the nature and role of money is central for designing a currency and its

\footnotetext{
${ }^{5}$ In fact, in the preface of the second edition of The alchemy of finance, Soros argues for a more integrated view of reflexivity theory and efficient market theory: "We may distinguish between near-equilibrium conditions where certain corrective mechanisms prevent perceptions and reality from drifting too far apart, and far-from-equilibrium conditions where a reflexive double-feedback mechanism is at work and there is no tendency for perceptions and reality to come close together without a significant change in the prevailing conditions, a change of regime. In the first case, classical economic theory applies and the divergence between perceptions and reality can be ignored as mere noise. In the second case, the theory- of equilibrium becomes irrelevant and we are confronted with a one-directional historical process where changes in both perceptions and reality are irreversible. It is important to distinguish between these two different states of affairs because what is normal in one is abnormal in the other".
} 
features. In effect, in order to engineering a particular crypto or digital currency we have to answer questions that are philosophical in kind, like what is money, what is its goal, how should it be backed, what is the relation between markets and States, and between economy and financial institutions, in forging money, and the centralization or decentralization of monetary process. For instance, the bitcoin is the result of an approach to the nature of money that draws on tenets like the decentralization and the absence of the States or financial institutions in the monetary process. These principles are of course debatableactually other digital or crypto currencies employ different principles-and these debates involve philosophical issues.

\subsection{Issues in Financial Ontology}

Financial systems are very complex from an ontological viewpoint. Leaving aside the much-debated ontologies of money, here it is important to note that unlike natural science, many financial objects are fast-changing by nature and can be subject to reflexive dynamics, that is, observations end expectations of the financial agents affect the behavior they are observing - and a given theory affects the behavior of the financial system that it aims at describing. These features have deep theoretical and practical consequences in financial systems and their understanding, and philosophy can help to handle them.

A common way of characterizing financial entities identifies at least two classes (see e.g. Merton \& Bodie, 1995; Chami et al., 2010): institutions and assets (stores of values).

In the first case, a financial entity is defined as one providing financial brokerage, that is, offering loans, capital investments, insurance. In this sense financial entities are banks (brokerage, investment, savings), insurance companies, central banks, and funds. Even if they have different functions, roles and scopes, basically they aim at creating a system that ensures a smooth functioning of the financial systems.

In the second case, a financial entity is characterized as an object of exchanges, that is, credit agreements and contracts such as bonds, equity like stocks, or derivatives (futures, options, ABS, swaps, CDO).

However, in the fast-moving world of finance, basic entities and their properties and relations often change very quickly producing a dynamic and liquid ontology that poses several problems to the financial theories and practice. Moreover, the nature of financial institutions and their relationships, and set of beliefs about them, can be modified by human decisions and technology and, therefore, it is not a surprise that the debates about financial ontology have become more intense. ${ }^{6}$

On one hand, technological innovation can be a relevant source of ontological instability. For instance, algorithmic finance has changed market dynamics, especially in stock markets, in a way that has undermined the ontological status of fundamental entities like the notion of 'quote', which has an unclear ontological status since in some algorithmic settings, as noted by O'Hara (2010). In effect, the way computers submit and manage orders seems to suggest that in certain scenarios a quote is no longer the simple expression of (real) supply and demand.

On the other hand, the boundaries between supposedly distinct entities can be crossed by the introduction of new policies, regulations and practices, which can blur these boundaries and undermine the ontological status of the financial entities. A remarkable example

${ }^{6}$ See e.g. Lehman and Mortensen (2019), Boldyrev (2019). 
is provided by the Central Banks (e.g. Japan and Switzerland). Gradually they have become more and more active financial players, that is, they invest in the markets by buying not only traditional assets like gold, but also shares of companies (like those of the Big Tech companies). In this way, they increasingly resemble an investment bank, reducing the distinction between two supposedly separate financial entities. As a consequence, their ontological status becomes less clear and what is a Central Bank becomes a legitimate question. Now, new ontological setups like these are puzzling as they can trigger behavior and consequences that are difficult to predict. The fact that a central bank owns shares of a private company not only raises several potential conflicts of interests, but it also conflicts with most of the contemporary ways of conceiving the relationship, and the boundaries, between financial institutions, and between financial institutions and the market.

In addition, the emergence of a new ontological setup like this it is difficult to interpret. In effect, on the one hand, it suggests that a dynamical financial ontology could prevent reaching states of equilibrium and a proper functioning of financial systems, which could then become more prone to instability and crises-or worsen a crisis when it strikes. On the other hand, it also suggests that in order to get certain goals, just like equilibrium and stability, some financial entities (like a Central Bank) have to change and adjust themselves to these dynamical ontologies.

This is just one example of an issue that requires a philosophical treatment in ontological, epistemological and methodological terms.

Moreover, the way we structure a financial ontology - the way we set up the basic entities, their properties and their relations-has deep consequences that impact also the methodology and epistemology of a theory. For example, a particular ontological setup determines if certain issues can be approached quantitatively or qualitatively, and, in the former case, by means of certain formal tools (a mathematical theory) but not by other ones. A typical example is statistical mechanics (see e.g. Voight, 2005), which requires to frame the financial entities in a very specific manner in order to be applied to them.

\subsection{Issues in Financial Methodology}

Developing a robust methodology for finance is known to be difficult not only for its complexity, but also for one of its distinctive features, i.e. reflexivity, which complicates further our prospects on achieving a systematic knowledge (a theory) about its dynamics. In effect, when predictions or even expectations can affect the behavior of the system that they refer to-as reflexivity implies - the system can behave in a manner that can defy these specific predictions or expectation, that is, in a way that could not be properly taken into account by a new prediction or expectation, as the Morgenstern's paradox points out (Morgenstern, 1935).

Leaving aside the traditional solutions to both Morgenstern's paradox and the problem of prediction in socio-economic settings (see. e.g. Grunberg \& Modigliani, 1954; Lehmann-Waffenschmidt, 1990; Henshel, 1995; Muth, 1961), it is worth noting here that this fundamental problem cannot be solved by telling apart private and public prediction, as for example Didier Sornette (2003) suggests. As a matter of fact, if a prediction or an expectation about the future state of a financial markets is not made public (it remains private), and if the agents producing the prediction do not act on it (i.e. do or do not invest), it seems plausible to think that that prediction will not affect the system to which it refers, since the system will not react to it. Therefore, if I make a prediction and I keep it secret 
without acting accordingly, I could be in a position to check if the prediction is right or wrong. So far, so good.

But what does it really mean to make a 'private' prediction? What line of events is it really predicting? In effect, at a closer look a private prediction does predict the behavior of financial system in which this prediction has not been made public, and then it predicts a line of events that is different from the line of event where it has been made public. Basically, the private and the public predictions are predicting two different future states-one in which the prediction is not made public and acted on, and one in which this has been made public and acted on. This central feature of financial markets explains also why policy makers should take into consideration the effect of policies on the systems that they regulate, that is, the way the systems can react and adjust to them, when certain policies are put in place.

Accounting for the effect of a prediction or expectation on a financial system is central for developing a theory and a reliable method for it. The several theories on financial markets try to solve methodological issues like this in different ways, and philosophy, in particular logic and philosophy of science, helps us to clarify the relations between these theories, and their strengths and weaknesses. For instance, the efficient market theory employs a methodological individualism, whereas econophysics uses an emergentist one, which is a consequence of the fact that they rely on different ontologies.

But the question remains open: how do we produce reliable knowledge about financial systems? Here we can advance several answers. One is by using two main views, that is an internal or an external one (see Ippoliti, 2017a, 2017b; Chen, 2019).

The internal view maintains that in order to study, understand, and profit from financial markets, it is necessary to acquire as much knowledge as possible about their internal machinery: institutions, regulators, rules of trade executions, laws, the behavior and psychology of traders and investors. A formal or mathematical treatment does not necessarily play a central role in this approach.

The external view maintains that we can make sense of financial markets by looking for patterns and regularities in sets of data, and it holds that it can be detected and studied through mathematics.

Of course, these two methods can be combined, and philosophy helps us to build a balanced approach to financial problems for both their quantitative and qualitative side. Even if it this does not means that it can offer a solution to the problem of prediction, however it can help finance to produce better and better models that can help to better manage risk and counteract the effects of financial crisis.

\subsection{Philosophy and Mathematical Finance}

Even if the histories of finance and mathematics are intertwined (see e.g. Akyıldırım \& Soner, 2014 for a brief summary), the idea of a systematic mathematical modelling of financial phenomena is relatively recent, and it plays a crucial role in understanding and predicting their dynamics. In effect, on one hand not every theory on financial systems ends up with a mathematical treatment of them, while on the other hand not every mathematical theory provides us with useful or reliable predictions. A stock example is Mandelbrot's 
fractal theory, whose sensitivity to initial conditions combined with typical rounding errors in financial markets make its predictions untrustworthy. ${ }^{7}$

Philosophy helps us to understand both the role that mathematics plays in modelling financial markets, especially stock markets, and how a mathematical approach to finance could and should be built. In effect, there are several mathematical approaches to financial markets like econometrics, econophysics, and 'financial physics', and they raise not only methodological, epistemological, and even ethical issues, but also descriptive and normative problems-for example, if mathematical finance is a tool for describing certain financial dynamics or also for understanding how to regulate it.

The standard way of building a mathematical finance is by employing a top-down approach. We can break down this approach into at least two stances, which are not mutually exclusive:

S1. The financial-physical approach, which employs and adjusts know mathematical theories, mostly mathematical physical theories (e.g. statistical physics), to certain financial phenomena, or vice versa, in order to treat them by means of a known mathematical theory on the basis of certain similarity between the financial phenomena and these theory.

S2. The axiomatic-deductive approach, which builds a set of axioms in order to create a plausible financial world and then derives consequences from it, a là Friedman (1953).

This means that such a top-down approach is not neutral, if there is such a thing, as it embeds hypotheses and assumptions whose content is tentatively extended to financial phenomena and that deeply shapes the way we construct a mathematical treatment for them. That is, such an approach embeds a specific philosophical and theoretical view-a stock example is the so called 'philosophy of equilibrium' contained in many mathematizations of financial markets (see Clark, 1986).

Of course, this approach is a legitimate and economic way of building a mathematical finance (see also Ippoliti, 2020a, 2020b). In more detail, the strategy of S2 is to use axioms (which embed hypotheses on financial entities) and deductively draw conclusions from them. Its main challenge is the plausibility and 'realism' of the axioms, and the assessment of conclusions from unrealistic assumptions. The prototype of this approach is the homo oeconomicus. It is characterised by a set of axioms that assumes "ideal" properties such as perfect rationality, self-interest, and optimality in pursuing subjectively-defined ends, which are used to draw conclusions on the effects of his behaviour.

$\mathrm{S} 1$ uses known formal solutions in order to model and solve certain financial problems - it is a way of deductively anticipating solutions for possible scenarios. Its main challenge is to understand how to apply an (already known) formal solution to the problem at stake. This strategy has important weaknesses too. The main one is selectivity: using a specific mathematical theory to approach a financial problem might lead us to focus only on those features that can be modelled by it, but which may not be those essential to understand the problem. Many current mathematical approaches to finance display this

\footnotetext{
7 For example, if our initial measure of a stock's value is out by 1/10th of a percent-let us say $9456.4 €$ instead of $9456.5 €$ - after one day or one time iteration, the fractal model would be wrong by $1 \%$; one day later by $10 \%$; and a day after that, it would be completely useless as a means of predicting the following day's value. Any measurement error we make in specifying the initial conditions of a fractal model grows exponentially with time.
} 
weakness. A stock example is the use of Brownian motion in finance (see Walter, 2020 also for epistemic issues of Brownian motion).

More generally, the priority of S1 and S2 is to search for similarities between financial phenomena and other known (typically physical) phenomena, which already have a mathematical treatment, and this strategy leads to hasty and risky assimilations between phenomena that could in fact be essentially different, so preventing a genuine understanding of the specific properties of financial phenomena.

The other way of building a mathematical view of finance is by means of a bottom-up approach, which overturns this perspective. It tries to understand and describe the financial phenomena in a qualitative and verbal way, and then, in case, to produce a mathematical characterization of them. Of course, this road can be much more difficult than the top-down. First, the process does not guarantee that the outcome will be a mathematical theory-while in the top-down approach this is guaranteed from the very beginning. As a matter of fact, the bottom-up way of building a theory may not go beyond a verbal and qualitative description of a financial phenomenon. In addition, even if this phase is passed, it may be necessary to develop new mathematics in order to model that phenomenon formally_a task that usually requires time.

The main advantage of this approach is the that its priority is the deep understanding of the financial phenomena and their specificity. An example of a bottom-up approach to financial phenomena is provided, again, by Mandelbrot's fractal theory, which is a new mathematical tool that approximates the financial data in a much more cogent and plausible way than the efficient market hypothesis, which instead is highly selective and assumes the goodness of Brownian motion without justifying it (see Ippoliti, 2013). Nevertheless, the fractal theory does not offer a real answer to the qualitative side of the problem, as it cannot provide an explanation of features and trajectories of stock markets in terms of the behaviour and decisions of the investors. ${ }^{8}$

Last but not least, a relevant and much debated issue in mathematical modelling of finance is their performativity, that is, their power of aligning the behavior of the market with the prediction provided by those models. In this respect, a less developed point is the study of the limits of performativity in finance, namely, to what extent these models can bend the target system ('reality') before it gets recalcitrant or even strikes back. ${ }^{9}$ An interesting case study in this respect is the models employed in monetary policies (e.g. the ones used by Central Banks). In effect, these models are particularly relevant here since they are explicitly designed to be performative, that is, to affect the system in order to align it with the predictions provided by these models - to achieve the goals that a Central Bank is trying to make happen. This leads us directly to another important issues in a mathematics of finance, that is, the responsible construction and use of mathematical products in

\footnotetext{
${ }^{8}$ In a nutshell, Mandelbrot's theory shows that the idea that financial price movements are random is incorrect, but it remains a way to characterize the statistical properties of the market, and it is not a theory about how the market actually behaves. The only salient qualitative contribution that it offers, as noted by Peters (1994), Keen (2011), is the explanation of the conditions of stability of the markets that contradicts the Efficient Market Hypothesis. In effect, it supports the idea that the markets will be stable when "it allows investors with different time horizons to trade smoothly. As a result, heterogeneity - the fact that all investors are not the same-is a vital part of this theory".

(Keen 2011, p: 341). That is, it explains the stability of the market starting from a more plausible assumption, namely, that investors differ in their time horizons, and it also suggests a plausible cause of instability, which should happen when all investors suddenly converge to the same time horizon.

9 See Brissett 2019 for an attempt to conceptualize it.
} 
finance due to their performative power, which is still relatively an unexplored issue, and that philosophy can help to develop. In effect, if a mathematical model can perform, in the technical sense, a market, then its construction and employment should be publicly share, discussed and revised.

\section{Finance for Philosophy}

If finance needs philosophy, especially now that financial markets are a central infrastructure of contemporary societies, it is worth noting that we can argue the other way around, too: financial phenomena do offer interesting material for traditional philosophical issues. To mention just some examples, finance raises interesting questions about the relationship between theory and practice (Sect. 3.1), the relationship between data and hypothesis-and hence theory building (Sect. 3.2) — and the relationship between three fundamental notions such as explanation, prediction and control (Sect. 3.3). These issues have been addressed repeatedly in the philosophical treatment of other disciplines. For instance, the philosophy of physics (see Duhem, 1906, 1908) has shown that the relation between data and hypotheses is under-determined and theory-laden. The study of finance shows that not only do these two properties hold in social domains, that is, hypotheses (and theories) and data are not independent, but also that a kind of circularity between them can take place so that the price of a stock (its numerical value) and the hypothesis about it affect each other in a way that has deep philosophical consequences. For example, the philosophy of big data and its inductivist approach - the idea that we can analyze the data without hypotheses about what they might show (Anderson, 2008) ${ }^{10}$ —would be ineffective or defective in stock markets. There are situations where prices (data) are the outcome of certain theories employed by the agents and it would be misleading to try to use those prices as the key to generate new theories about that market, as these theories are already producing those prices, which would be different without them. In these situations, the data do not speak for themselves, and the prediction of future prices would be highly unreliable if it is based simply on the past prices. In addition, we can end up with a conflict between the new theory and those that produce the original prices, and this conflict will engender new prices.

The financial crisis of 2007-08 is a good example in this sense, as it shows that throwning big numbers into the big computing clusters did not help financial analysts and their statistical algorithms to find patterns foreseeing one of worst crisis in the financial history of the world.

\subsection{Theory and Practice in Finance}

One of the most interesting features in financial systems, and especially in stock markets, is the relation between theory and practice, that is, the theoretical products and the world of agents and practices that they aim at describing. In effect, the presence of performative and constructive mechanisms in finance puts these theoretical products in a position to shape social interactions - at least a part of them and at least temporarily - in a way that is hard to encounter in other social domains. In particular, the employment in the financial markets

${ }^{10}$ For a criticism of the philosophy of big data see Cellucci (2018). 
of models ${ }^{11}$ and socio-technical devices, like algorithms or formulas, can generate dynamics that raises a crucial issue, namely the possible production of the outcome predicted or expected by these models. ${ }^{12}$ This property makes theory and practice so intertwined in financial markets that in some cases one can work on the theoretical product to 'adjust' portion of the world (see Boldyrev \& Ushakov, 2016).

Thus, if we accept the thesis that theoretical tools are able to shape a system in the way predicted by them, hence a portion of a financial market can be designed following a specific model in a way that (temporarily) pushes financial actors to fit in with it, rather than vice versa. That is, a model becomes a way of intervening and not simply of describing. When this happens, a sort of 'reverse finance' emerges (see Ippoliti, 2019) and we could start from the model and then try to produce the corresponding 'reality', or better, we could start from the wanted outcome, the one predicted by the model, and then try to engineer as much as possible (with norms, rules, technologies) the hypotheses of the model needed to produce that specific outcome so that the market will behave as the model predicts. Several financial tools, for example algo-trading or high frequency trading, could be viewed in this way, that is, as a (legal) way to obtain certain outcome in this reversing fashion.

In more detail, reverse finance can investigate what are the possible initial conditions, and processes, needed to obtain an intended result, or better, it can investigate which hypotheses (conditions) are necessary to get a specific financial result, which is the starting point of the investigation. Thus, we set a wanted goal and then we try to find the hypotheses and processes that, if satisfied, would produce it. Moreover, since a given outcome T can be obtained from several sets of initial conditions (hypotheses), reverse finance can investigate what is a minimal "natural' ${ }^{13}$ set of them that is capable of getting T. In doing so, we can show that specific hypotheses are necessary for $\mathrm{T}$, while others are not, and that they can be eliminated or replaced with other ones. For instance, the monetary policy models used by central banks, which are explicitly intended to be performative, would benefit a lot from such an approach.

Of course, in order to be effective this reversal has to specify how processes and conditions that are only possible can become actual - and then what normative context, rules, conditions of a market must hold or change at a given time in order to produce the wanted outcome. ${ }^{14}$ In this sense, a model would a be way of determining the conditions that have to be met by the market ('reality') in order to obtain the event predicted by the model ('theory'). In effect, some of the initial conditions needed to activate certain mechanism are at work in the markets, while others not, and we have to generate them in some way in order to trigger the appropriate chain of events that produces the wanted outcome, that is, the one implied by the model. Usually, the trigger is provided by certain orders or trades, which generate a sequence of actions and reactions that changes the state of a financial system at a given time $t$ and push the systems towards the outcome predicted by the theoretical product. In this way, a theorical product can shape financial practice and make certain things happen.

\footnotetext{
11 See Brisset (2018), Svetlova (2012), Svetlova, Dirksen (2014).

12 See Callon (1998, 2007), MacKenzie (2006), MacKenzie et al. (2006), Brisset (2019).

13 'Natural' here means the initial conditions and processes that better fit a specific financial set-up at a given time $t$.

14 A factor affecting these conditions is the time horizon: as it increases, the possible reversal becomes less and less likely to get or to maintain.
} 


\subsection{Data and Hypothesis in Finance}

Another philosophical issue that finance helps to understand better is the relation between data and hypothesis. ${ }^{15}$ In effect, if the performative thesis is right, the notion of data in finance becomes elusive in certain financial market's settings, in the sense that data are 'theory-laden' and there is a circularity between data and hypothesis. Financial data, especially in the stock markets, are not independent of the hypotheses about the financial system, and they are the direct outcome of these hypotheses, at least in some cases. The active role played by models and socio-technical devices is essential in this sense: a model like a financial formula or an algorithm and their set of hypotheses, once employed, can temporarily perform parts of a financial market by producing specific sequence of data (prices, etc.) that could not be produced if these hypotheses were not formulated and employed.

Thus, if we accept that the performative thesis is a sensible way of accounting of certain dynamics of financial markets, it follows that it would support certain tenets of philosophy of science and not others. In particular, they support the idea that data are not neutral and objective starting points of an inquiry, but that they are dependent on our theories (see Sellars, 1956; Cellucci, 2017).

First, financial markets add a new page to the study of the relation between models and data. On the one hand, they challenge the role of models from an ontological viewpoint, since the distinction between 'model' and 'reality', between models of a system and the system itself, can short-circuit here. In effect, under certain circumstances we cannot tell if a model is a description of 'reality', or if 'reality', and its data flow, is simply the outcome of this model. Furthermore, this implies that in these circumstances we cannot count on simple quantitative approaches in order to account for regularities and patterns and foresee markets dynamics, because the hypotheses embedded in the model would be the engine that produces the data flow.

Secondly, the way models, data and phenomena are intertwined in financial systems undermines a classical taxonomy such as the one that tells apart 'models of data', 'models of phenomena', 'models of theory' (see Suppes, 1966). As we have seen, the specific features of financial systems make it difficult to distinguish between data, phenomena and theory: data flaws are theory and model-laden, while a phenomenon can be the provisional outcome of a specific model employed in a financial market.

Thirdly, the circularity between models and data, both theoretically and practically, opens the way to possible exploitations and manipulation of financial market by means of an appropriate use of specific models and data. In effect, since neither data nor models, at least under certain circumstances, are simply descriptions of a target system, the distinction between performativity and manipulation might become very thin, especially at microlevels in stock markets.

This issue raises another interesting philosophical theme, namely the role of narrative (see Shiller, 2019) in finance-narrative finance in short. In particular, the process that guide the choice of a specific model over another one relies also on a discourse, which employ both scientific and non-scientific arguments in order to back the acceptance of such a model. This narrative-backed model is then disseminated and, as it gets increasingly used by practitioners, can perform specific dynamics that shapes the data of the system, which will be affected in a way that is not visible, since they are simply an outcome of it. These

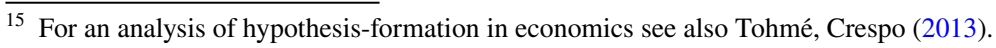


data, in turn, become the base for the action or reaction of part of the financial actors, who might not be aware of the 'theory-ladeness' of these data, and then they could be misled in several way, for instance by following a course of actions that can end up with a higher price for the ask side, or a lower price for the bid side.

\subsection{Prediction, Description and Control in the Light of Financial Systems}

If we accept that reverse finance is a reasonable way of accounting for specific dynamics of financial markets, it follows that there are cases where the notion of prediction, description, and control and their relations and distinctions become puzzling.

In effect, the peculiar nature of the financial relations between models and data, between reality and theoretical products, paves the way for possible manipulation of stock markets through an appropriate use of models. In fact, since neither data nor models, at least in certain circumstances, are simply representations or descriptions of a system, the 'reversal' becomes possible and the boundaries between performativity and manipulation get very thin.

Of course, not every model can be reversed in order to align a market with its expected outcome, but this possibility increases under certain conditions (see also Svetlova, 2012; Svetlova \& Dirksen, 2014 on this point). For instance, it increases by means of two factors: the time-lapse between when the model makes its prediction and when the predicted event should happen, and how much a market is run by algorithms (see Ippoliti, 2019).

Thus, in principle it would be possible to start from the prediction of a model, even a non-representational one (Grune-Yanoff, 2013), and then make the initial conditions required by this model real, and so align the market temporarily with the outcome implied by the model itself. Thus, the prediction of a possible results can become a literal description, and this description can become a way of controlling (temporarily) a market. In this way, we can engineer an intended outcome by looking for the most 'natural' model that would produce that outcome under a specific financial scenario. In this case, reverse finance it is a way to understand how to change or design the actual financial scenario (form a normative, practical, technological, and narrative viewpoint) in order to get an intended outcome. Prediction, representation and control would be in part reversible processes, and it would be possible to move from one to the other, to get one from the other, in a way that is not possible in other domains. This shows how finance can help us to rethink a few features and connections between these three basic notions that have been traditional objects of philosophical reflection.

Acknowledgements I would like to thank the anonymous referees for their valuable advice.

Funding Open access funding provided by Università degli Studi di Roma La Sapienza within the CRUICARE Agreement. No funding.

\section{Declarations}

Conflict of interest The author declares that he has no conflict of interest.

Ethical approval This article does not contain any studies with human participants performed by the author. This article does not contain any studies with animals performed by the author.

Open Access This article is licensed under a Creative Commons Attribution 4.0 International License, which permits use, sharing, adaptation, distribution and reproduction in any medium or format, as long 
as you give appropriate credit to the original author(s) and the source, provide a link to the Creative Commons licence, and indicate if changes were made. The images or other third party material in this article are included in the article's Creative Commons licence, unless indicated otherwise in a credit line to the material. If material is not included in the article's Creative Commons licence and your intended use is not permitted by statutory regulation or exceeds the permitted use, you will need to obtain permission directly from the copyright holder. To view a copy of this licence, visit http://creativecommons.org/licenses/by/4.0/.

\section{References}

Ackert, L., \& Deaves, R. (2009). Behavioral finance: Psychology, decision-making, and markets. Cengage Learning Inc.

Akyıldırım, E., \& Soner, H. M. (2014). A brief history of mathematics in finance. Borsa Istanbul Review, 14, 57-63.

Anderson, C. (2008). The end of theory: The data deluge makes thescientific method obsolete. Wired Magazine, 16(7), 16-17.

Austin, J. L. (1962). How to do things with words. Harvard Univ. Press.

Bertolotti, T., \& Magnani, L. (2017). Contemporary finance as a critical cognitive niche. In P. Chen \& E. Ippoliti (Eds.), Methods and finance (pp. 129-150). Springer.

Boldyerv, I., \& Ushakov, A. (2016). Adjusting the model to adjust the world: Constructive mechanisms in postwar general equilibrium theory. Journal of Economic Methodology., 23(1), 38-56.

Boldyrev, I. (2019). The ontology of uncertainty in finance: The normative legacy of general equilibrium. Topoi. https://doi.org/10.1007/s11245-019-09646-5

Brisset, N. (2018). Models as speech acts: The telling case of financial models. Journal of Economic Methodology, 25(3), 1-21.

Brisset, N. (2019). Economics and performativity. Exploring limits, theories and cases. Routledge.

Brook, Y. (2011). The morality of money lending: A short history. In D. Ghate \& R. E. Ralston (Eds.), Why businessmen need philosophy (pp. 98-109). Penguin.

Butler, J. (1990). Gender trouble: Feminism and the subversion of identity. Routledge.

Callon, M. (1998). Introduction: The embeddedness of economic markets in economics. In M. Callon (Ed.), The laws of the markets. Blackwell.

Callon, M. (2007). What does it mean to say that economics is performative? In D. MacKenzie, F. Muniesa, \& L. Siu (Eds.), Do economists make markets? (pp. 310-357). Princeton University Press.

Cellucci, C. (2017). Rethinking logic. Springer.

Cellucci, C. (2018). Theory building as problem solving. In D. Danks \& E. Ippoliti (Eds.), Building theories. Heuristics and hypotheses in sciences (pp. 63-79). Springer.

Chami, R., Fullenkamp, C., \& Sharma, S. (2010). A framework for financial market development. Journal of Economic Policy Reform, 13(2), 107-135.

Chen, P. (2019). Market uncertainty, information complexity, and feasible regulation: An outside view of inside study of financial market. Topoi. https://doi.org/10.1007/s11245-019-09655-4

Clark, C. (1986). The philosophy of equilibrium. Quaderni Di Storia Dell'economia Politica, 7(2/3), 49-67.

De Bruin, B., Herzog, L., O’Neill, M., Sandberg, J., \& Zalta E. N. (Ed.). (2020). Philosophy of Money and Finance. The Stanford Encyclopedia of Philosophy. https://plato.stanford.edu/archives/win2020/entri es/money-finance/.

Dewey, J. (1920). Reconstructions in philosophy. The Beach Press.

Duhem, P. (1906). La théorie physique son objet et sa structure. Chevalier \& Riviere.

Duhem, P. (1908). Sōzein ta phainomena: Essai sur la notion de théorie physique de Platon à Galilée. Hermann.

Epstein, G. A. (2005). Financialization and the world economy. Edward Elgar Pub.

Fama, E. F. (1970). Efficient capital markets: A review of theory and empirical work. Journal of Finance, 25(2), 383-417.

Ferguson, N. (2008). The ascent of money: A Financial History of the World. Penguin.

Flanagan, O. J. (1981). Psychology, progress, and the problem of reflexivity: A study in the epistemological foundations of psychology. Journal of the History of the Behavioral Sciences, 17, 375-386.

Friedman, M. (1953). Essays in positive economics. University of Chicago Press.

Friedman, T. L. (1999). The Lexus and the Olive Tree: Understanding globalization. Farrar Straus \& Giroux. Garonna, P., \& Spaolonzi, F. (Eds.). (2016). Ethics in finance, finance in ethics. LUISS University Press. 
Grunberg, E., \& Modigliani, F. (1954). The predictability of social events. Journal of Political Economy, $62(6), 465-478$.

Grune-Yanoff, T. (2013). Appraising non-representational models. Philosophy of Science, 80(5), 850-861.

Hédoin, C. (2012). Philosophy and economics: recent issues and perspectives. Revue D'économie Politique, 128(2), 177-189.

Henshel, R. (1995). The grunberg/modigliani and simon possibility theorem: A social psychological critique. The Journal of Socio-Economics, 24(3), 501-520.

Ippoliti, E. (2013). Generation of hypotheses by ampliation of data. In L. Magnani (Ed.), Model-based reasoning in science and technology. Theoretical and cognitive issues (pp. 247-262). Springer.

Ippoliti, E. (2017a). Method and finance. A view from outside. In P. Chen \& E. Ippoliti (Eds.), Methods and finance. A unifying view on finance, mathematics and philosophy (pp. 3-15). Springer.

Ippoliti, E. (2017b). Method and finance. A view from inside. In P. Chen \& E. Ippoliti (Eds.), Methods and finance. A unifying view on finance, mathematics and philosophy (pp. 121-128). Springer.

Ippoliti, E. (2019). Models and data in Finance: les Liaisons Dangereuses. In Á. Nepomuceno Fernández, L. Magnani, F. J. Salguero-Lamillar, C. Barés-Gómez, \& M. Fontaine (Eds.), Model-based reasoning in science and technology (pp. 393-406). Springer.

Ippoliti, E. (2020a). Mathematics and finance: Some philosophical remarks. Topoi. https://doi.org/10. 1007/s11245-020-09706-1

Ippoliti, E. (2020b). Un filosofo a wall street. Milano.

Keen, S. (2011). Debunking economics. Zed Books.

Keynes, J. M. (1936). The general theory of employment, interest and money. Harcourt Brace and Co.

Kinley, D. (2018). Necessary evil: how to fix finance by saving human rights. Oxford University Press.

Lakatos, I. (1976). Proofs and refutations, the logic of mathematical discovery. Cambridge University Press.

Latour, B. (2005). Reassembling the social: An introduction to actor-network-theory. Oxford UP.

Lehman, G., \& Mortensen, C. (2019). Finance, nature and ontology. Topoi. https://doi.org/10.1007/ s11245-019-09654-5

Lehmann-Waffenschmidt, M. (1990). Predictability of economic processes and the morgenstern paradox. Swiss Journal of Economics and Statistics, 126(II), 147-161.

Lo, A. W. (2004). The adaptive markets hypothesis. The Journal of Portfolio Management, 30(5), 15-29.

MacKenzie, D. (2006). An engine, not a camera. MIT Press.

Mandelbrot, B. (1963). The variation of certain speculative prices. Journal of Business, 36, 394.

Mandelbrot, B. (2006). The misbehavior of markets: A fractal view of financial turbulence. Basic Book.

Mas-Colell, A., Whinston, M. D., \& Green, J. R. (1995). Equilibrium and its basic welfare properties. Microeconomic theory. Oxford University Press.

McCloskey, D. N. (1998). The rhetoric of economics (2nd ed.). University of Wisconsin Press.

Merton, R. K. (1948). The self-fulfilling prophecy. The Antioch Review, 8(2), 193-210.

Merton, R. C., \& Bodie, Z. (1995). A conceptual framework for analyzing the financial environment. In D. B. Crane, K. A. Froot, S. P. Mason, A. Perold, R. C. Merton, Z. Bodie, E. R. Sirri, \& P. Tufano (Eds.), The global financial system: A functional perspective (pp. 3-31). Harvard Business School Press.

Minsky, H. (1980). Capitalist financial processes and the instability of capitalism. Journal of Economic Issues, 14(2), 505-523.

Morgenstern, O. (1935). Perfect foresight and economic equilibrium. In A. Schotter (Ed.), Selected economic writings of oskar morgenstern (pp. 169-183). New York: New York University Press.

Muth, J. F. (1961). Rational expectations and the theory of price movements. Econometrica, 29(3), 315-335.

Nussbaum, M. C. (2016). Economics still needs philosophy. Review of Social Economy, 74(3), $229-247$.

O'Hara, M. (1995). Market microstructure theory. Blackwell.

O'Hara, M. (2010). What is a quote? The Journal of Trading, 5(2), 10-16.

Persky, J. (2007). Retrospectives: From usury to interest. The Journal of Economic Perspectives, 21(1), 227-236.

Peters, E. E. (1994). Fractal market analysis. Wiley.

Popper, K. (1957). The poverty of historicism. ARK Paperbacks.

Quine, W. V. O. (1981). Theories and things. Harvard University Press.

Rao, S. K. (2007). Algorithmic trading: Pros and cons. Tata Consultancy Services.

Ross, D. (2005). Economic theory and cognitive science: Microexplanation. MIT Press.

Searle, J. (1969). Speech acts: An essay in the philosophy of language. Cambridge University Press. 
Sellars, W. (1956). Empiricism and the philosophy of mind. In H. Feigl \& M. Scriven (Eds.), Minnesota studies in the philosophy of science, volume I: The foundations of science and the concepts of psychology and psychoanalysis (pp. 253-329). University of Minnesota Press.

Shiller, R. (2019). Narrative economics: How stories go viral and drive major economic events. Princeton University Press.

Simon, H. (1954). Bandwagon and underdog effects of election predictions. Public Opinion Quarterly, $18,245-253$.

Smith, A. (1759). The theory of moral sentiments. Millar.

Sornette, D. (2003). Why stock markets crash. Princeton University Press.

Soros, G. (1987). The alchemy of finance. Wiley.

Stiglitz, J. E. (1994). Whither socialism? MIT Press.

Sugden, R. (2000). Credible worlds: The status of theoretical models in economics. Journal of Economic Methodology, 7(1), 1-31.

Suppes, P. (1966). Models of data. In E. Nagel, P. Suppes \& A. Tarski (Eds.), Studies in Logic and the Foundations of Mathematics (Vol. 44, pp. 252-261).

Svetlova, E. (2012). On the performative power of financial models. Economy and Society., 43(2), $418-423$.

Svetlova, E., \& Dirksen, V. (2014). Models at work-models in decision making. Science in Context, 27(4), 561-567.

Tohmé, F., \& Crespo, R. (2013). Abduction in economics: A conceptual framework and its model. Synthese, $190(18), 4215-4237$.

Voit, J. (2005). The statistical mechanics of financial markets. Springer.

Walras, L. (1900). Eléments d'économie politique pure. Rouge.

Walter, C. (2020). The brownian motion in finance: An epistemological puzzle. Topoi. https://doi.org/10. 1007/s11245-019-09660-7

Publisher's Note Springer Nature remains neutral with regard to jurisdictional claims in published maps and institutional affiliations.

Emiliano Ippoliti graduated cum laude in Philosophy at Sapienza University of Rome. He took his Ph.D. in Logic and Epistemology at Sapienza University of Rome (2005) and he was visiting scholar at Penn State University (2008). His main research interests are: a) Philosophy of mathematics-especially the heuristic approach in mathematics - and the logic of discovery. He has explored the heuristic role of mathematical representations and the inferential approach to problem-solving in mathematics. b) Philosophy and finance. He has explored the mutual relations between philosophy and finance, and methodological, ontological, and mathematical issues around finance. His focus is on the modelling of financial systems and its philosophical set-up and consequences. 